\title{
Letters
}

Website: www.bmj.com

Email: letters@bmj.com

\section{Hypoxic responses in infants}

\section{Subjecting infants to low oxygen} concentrations seems unethical

EDITOR-The ethics of Parkins et al's study depend partly on whether there is any potential benefit to the infants from the experiment. ${ }^{1}$ If parents subject their infant to low oxygen concentrations in an aeroplane they take a risk which is balanced against the benefit of air travel. Unless there is some real prospect of identifying infants at risk and offering useful protection against the sudden infant death syndrome, it seems to me to be unethical to subject those infants to the risk of exposure to low oxygen concentration. The fact that some of the families had previously experinced the loss of a child may have increased the likelihood of compliance. This makes me even more worried about the ethics of the study.

Charles West General practitioner

Church Stretton Medical Centre, Church Stretton, Shropshire SY6 6BL

1 Parkins KJ, Poets CF, O’Brien LM, Stebbens VA, Southal DP. Effect of exposure to $15 \%$ oxygen on breathing patterns and oxygen saturation in infants: interventional study. [With commentary by J Savulescu and V Hughes and authors' reply.] BMJ 1998;316:887-94. (21 March.)

\section{Research should contain element of treatment}

EdITOR-Parkins et al and Hughes, the chairman of the local ethics research committee, in their reply to the commentary by Savulescu, repeat that the parents knew of the potential risks and gave consent. ${ }^{1}$ This does not justify the research. In the case of proxy consent the people-in this case the parents-vested with that power must use it reasonably. The law regarding the participation of children in non-therapeutic research is unclear. The most favourable suggestion, from the researchers' point of view, is that the validity of consent should be based on whether the parents are clearly not acting against the best interests of the child. Thus the amount of risk that the child is exposed to becomes relevant. ${ }^{2}$

According to the British Paediatric Association it would be unethical to submit child subjects to more than minimal risk when the research offers no or minimal benefit to them. ${ }^{3}$ The Institute of Medical Ethics has defined minimal as a risk of death of less than 1:1000 000, a risk of major complications of less than 1:100 000, and a risk of minor complications of less than 1:1000. ${ }^{4}$ Parkins et al's study would have to be repeated almost 3000 times without major complication for the risk to be classified as minimal. The authors report an oxygen saturation of $<60 \%$ for 30 seconds in one child and of $<80 \%$ for over two minutes in another. Incidents such as these would be classified as major complications by anyone.

Much of the criticism could have been shortened if the study had been undertaken in infants who were to travel on aircraft, as suggested by Savulescu. This would have introduced an element of treatment. Collaboration with an airline would have made the study more cumbersome to undertake, but the convenience of the researchers cannot be used as an excuse for the participation of vulnerable volunteers.

Perhaps I am horrified by this study because I am an anaesthetist. The lowest acceptable inspired oxygen concentration during anaesthesia is $30 \%$. I doubt whether there are many who would think it acceptable for me to undertake research by deliberately inducing hypoxia in patients in my care, even if they were capable of consenting.

Nicholas Pace Vice-chairman

Local Research Ethics Committee, West Glasgow

Hospitals University NHS Trust, Glasgow G11 6NT

1 Parkins KJ, Poets CF, O'Brien LM, Stebbens VA, Southal DP. Effect of exposure to $15 \%$ oxygen on breathing patterns and oxygen saturation in infants: interventiona study. [With commentaries by J Savulescu and V Hughe and authors' reply.] BMJ 1998:316:887-94. (21 March.)

2 Pace N. Children. In: Scott WE, Vickers MD, Draper H, eds Ethical issues in anaesthesia. London: Butterworth Heinemann, 1994:86-96.

3 British Paediatric Association. Guidelines for the ethical conduct of medical research involving children. London: BPA, 1992

4 Institute of Medical Ethics. Medical research with children : ethics, law and practice. Bulletin of Medical Ethics 1986;14:8.

No known mechanism links hypoxia and sudden infant death syndrome

EDITOR-Parkins et al's study prompts comment on its misinterpretation of published material, flaws in study design, and conjecture in relating the experimental observations to risk of the sudden infant death syndrome. ${ }^{1}$ Our study of arterial oxygen saturation in Tibetan and Han infants born in Lhasa, Tibet, ${ }^{2}$ was wrongly cited in support of the hypothesis that hypoxia increases the risk of apparent life threatening events and sudden death in infancy.

Our results related to subacute infantile mountain sickness, a form of pulmonary hypertension and right heart failure. ${ }^{3}$ This syndrome has a slow onset and clear patho- logical abnormalities; it is not similar to the sudden infant death syndrome.

Parkins et al's study is compromised by looking at a sample with several identifiable risk factors for abnormal oxygen transport, pulmonary function, and control of breathing. Characterisation of the outcome measure (saturation $\leqslant 80 \%$ for $\geqslant 1$ minute) as "severe" and "prolonged" desaturation is a function of the testing procedureadministration of $15 \%$ oxygen at sea level-and has little relevance to physiology at high altitude.

Our observations at $3100 \mathrm{~m}$ in Leadville, Colorado, United States, have shown that healthy infants routinely experience arterial oxygen saturations $<80 \%$ during sleep; some have a slower postnatal fall in pulmonary artery pressure compared with at sea level. ${ }^{4}$ Recent studies showed periodic breathing accompanied by fluctuating arterial oxygen saturation in infants who were 1 week to 3 months old. ${ }^{5}$ Four of 35 infants had repetitive desaturations $<60-70 \%$ in the first 10 days of life. Two more developed pulmonary hypertension. There is no basis to equate these findings with the sudden infant death syndrome.

Finally, we question the assumptions that link airway hypoxia and the sudden infant death syndrome. What is the postulated mechanism that would cause death hours or days after return to sea level? The subjects were not monitored for

\section{Advice to authors}

We prefer to receive all responses electronically, sent either directly to our website or to the editorial office as email or on a disk. Processing your letter will be delayed unless it arrives in an electronic form.

We are now posting all direct submissions to our website within 72 hours of receipt and our intention is to post all other electronic submissions there as well. All responses will be eligible for publication in the paper journal.

Responses should be under 400 words and relate to articles published in the preceding month. They should include $\leqslant 5$ references, in the Vancouver style, including one to the BMJ article to which they relate. We welcome illustrations.

Please supply each author's current appointment and full address, and a phone or fax number or email address for the corresponding author. We ask authors to declare any conflicts of interest.

Letters will be edited and may be shortened.

www.bmj.com

letters@bmj.com 
hypoventilation, inequalities in ventilation: perfusion ratio, or reactive pulmonary hypertension in the time of interest (14-41 hours) after hypoxic challenge. The authors create a link between airway hypoxia and the sudden infant death syndrome through the example of hypoxaemic episodes that can complicate bronchiolitis. It is important not to blur the distinction between the sudden infant death syndrome and recognised clinical entities, such as pulmonary hypertension or bronchiolitis.

The exposure of infants to $15 \%$ oxygen yielded little information about physiology at high altitude or the sudden infant death syndrome. It did serve to create fear among parents planning air travel or visits to high altitude with young infants and to obscure understanding of the causes of infant mortality at high altitude worldwide.

Susan Niermeyer Associate professor of paediatric University of Colorado School of Medicine, Section of Neonatology, Children's Hospital, Denver CO 80218, USA

Lorna Grindlay Moore Professor of anthropology and medicine

University of Colorado, Denver and Health

Sciences Center, Cardiovascular Pulmonary

Laboratory, Denver CO 80262, USA

1. Parkins KJ, Poets CF, O'Brien LM, Stebbens VA, Southal DP. Effect of exposure to $15 \%$ oxygen on breathing patter parth [With come J Savulescu and V Hughes .

Niermeyer S, Yang P, Drolkar S, Zhuang J, Moore LG. Arterial oxygen saturation in Tibetan and Han infa born in Lhasa, Tibet. N Engl J Med 1995;333:1248-52.

3 Sui GJ, Liu YH, Cheng XS, Anand IS, Harris E, Harris P, e al. Subacute infantile mountain sickness. J Pathol 1988; $155: 161-70$

4 Niermeyer S, Shaffer EM, Thilo E, Corbin C, Moore LG. Arterial oxygenation and pulmonary arterial pressure in healthy neonates and infants at high altitude. J Pediat 1993;123:767-72.

5 Niermeyer S, Shaffer E, Moore LG. Impaired cardiopulmonary transition at high altitude. Pediatr Res 1998;43: 292A

\section{Danger to babies from air travel must be small}

EDITOR-Parkins et al's study has added to our understanding of the response to modest hypoxia in infancy. ${ }^{1}$ Unfortunately, however, media reports of the study have provoked public fear about the safety of air travel for young babies, and in particular their risk of subsequent sudden infant death syndrome.

As we were aware of the two cases of the sudden infant death syndrome that occurred after long haul air travel and were alluded to in Parkins et al's paper, we included questions about air travel in the previous month in the questionnaire used in the final year of the confidential inquiry into stillbirths and deaths in infancy and sudden unexpected death in infancy, 1995-6. The study covered a population of 17.7 million people, and $93 \%$ of parents of babies who had died of the sudden infant death syndrome participated. We have data on 130 cases of the syndrome and 528 controls. None of the babies who had died had flown in the month before-in fact, none had ever made an air journey-whereas two controls had. If the controls were representative of the general population the incidence of air travel would be 1 in 250 infants per year, so roughly 2400 infants would travel by air in the United Kingdom every year on nondomestic flights. If there is any danger to infants from air travel it must therefore be very small.

If we are ever in danger of forgetting the hazards of extrapolating clinical research findings from one situation to another we should remember that for many years mothers were advised to sleep their healthy term babies in the prone position, on the basis of physiological studies in preterm babies. The reversal of this advice, and the consequent reduction in the rate of the sudden infant death syndrome, remains a triumph of applied epidemiology over clinical science.

M P Ward Platt Consultant paediatrician Newcastle Neonatal Service, Royal Victoria Infirmary, Newcastle upon Tyne NE1 4LP

PJ Fleming Professor of infant health and developmental physiology, Institute of Child Health

P S Blair Medical statistician, Foundation for the Study of Infant Deaths Unit

C E A Leach Research assistant, Foundation for the Study of Infant Deaths Unit

Bristol Royal Hospital for Sick Children, Bristol BS2 8BJ

J Golding Professor of paediatric and perinatal epidemiology

Unit of Paediatric and Perinatal Epidemiology, Bristol BS8 1TQ

I Smith Senior lecturer in health services research Nuffield Institute for Health, Leeds LS2 9PL

1 Parkins KJ, Poets CF, O'Brien LM, Stebbens VA, Southall DP. Effect of exposure to $15 \%$ oxygen on breathin patterns and oxygen saturation in infants: interventiona study. [With commentaries by J Savulescu and V Hughes and authors' reply.] BMJ 1998;316:887-94. (21 March.)

\section{Study methods need to be appropriate}

EDIToR-The methods Parkins et al used in their study were flawed and the reported data underanalysed and overinterpreted. Hypoxia causes a multisystem response that includes effects on arterial oxygen saturation, heart rate (cardiac output), breathing pattern and effective ventilation, and arousal state

The arousal state modifies cardiorespiratory control and thus the response to hypoxia. ${ }^{2}$ These should have been measured and analysed before a conclusion could be drawn that responses were unpredictable and implied risk. Guidelines have been published for investigations that take account of these interrelations. ${ }^{3}$ These investigations are non-intrusive and different from those used by Parkins et al, which failed to prove the hypothesis.

Parkins et al contradict themselves in reporting that electrocardiography was used in their study, but reporting further down that it was not used. Only arterial oxygen saturation was used to assess hypoxic responsiveness, but it is sensitive to movement and two of six infants were erroneously withdrawn. The beat to beat mode does not improve accuracy of measurement but is more subject to motion artefact than averaging modes commonly used. Baseline data were reported only in relation to regular breathing, which was claimed to represent quiet sleep on the basis of a study that did not measure sleep. ${ }^{4}$ Periodic breathing normally occurs in quiet and active sleep, with arterial oxygen saturation cyclically below $90 \%$, which increases with hypoxia and hyperthermia. ${ }^{2}$ Three of 20 healthy newborn infants responded to hypoxia with periodic breathing, lower transcutaneous oxygen tensions, and higher transcutaneous carbon dioxide tensions. ${ }^{5}$ Some infants as well as some adults thus normally respond this way when they are asleep. Is the blue bloater distinguishable from the pink puffer at birth?

Parkins et al analysed only $27 \%$ (confidence interval $0 \%$ to $53 \%$ ), $16 \%$ ( $0 \%$ to $44 \%$ ), and $25 \%(0 \%$ to $83 \%)$ of periods spent in regular breathing pattern before, during, and after hypoxic challenge. This is hardly a representative sample period or a safe monitoring method. An arterial oxygen saturation value $<80 \%$ for $>60$ seconds is an arbitrary cut off and does not justify the clinical and alarming term severe hypoxaemia. We recently completed a study (table) during which we observed episodes of low arterial oxygen saturation in healthy infants during sleep while they were breathing air.

Measurements of arterial oxygen saturation vary. To have based such an important and emotionally charged study and conclusions, such as defining risk, on such inadequate methods and analysis is not acceptable. Investigators, funding agencies, and ethics committees should be aware of appropriate methodology.

Paul Johnson Consultant clinical physiologist Nuffield Department of Obstetrics and Gynaecology, John Radcliffe Hospital, Oxford OX3 9DU

1. Parkins KJ, Poets CF, O'Brien LM, Stebbens VA, Southall DP. Effect of exposure to $15 \%$ oxygen on breathing patterns and oxygen saturation in infants: interventiona study. [With commentaries by J Savulescu and V Hughes and authors' reply.] BMJ 1998;316:887-94. (21 March.)

2 Johnson P, Andrews DC. Thermometabolism and cardiorespiratory control during the perinatal period. In: Beckerman RC, Brouillette RT, Hunt CE, eds. Respiratory control disorders in infants and children. Baltimore: Williams and Wilkins, 1992;76-88.

3 Brookes LJ, Davidson-Ward SL, Hoppenbrauwers T, Johnson P. Cardiorespiratory polygraphic monitoring during sleep. In: Stocks JS, Sly PD, Tepper RS, Morgan WJ, eds. Infant respiratory function testing. New York: Wiley Liss USA, 1996; $485-520$.

4 Tappin DM, Ford RPK, Nelson KP, Price B, Macey PM,

Tappin DM, Ford RPK, Nelson KP, Price B, Macey PM,
Dove R, et al. Breathing, sleep state, and rectal temperature Dove R, et al. Breathing, sleep state, and rect
oscillations. Arch Dis Child 1996;74:427-31.

Low arterial oxygen saturation in healthy infants during sleep

\begin{tabular}{|c|c|c|c|c|c|c|c|}
\hline \multirow[b]{2}{*}{ Age } & \multirow[b]{2}{*}{$\begin{array}{c}\text { Infants } \\
\text { (No) }\end{array}$} & \multirow{2}{*}{$\begin{array}{l}\text { Recording time } \\
\text { for each infant } \\
\text { (hours) }(95 \% \mathrm{Cl})\end{array}$} & \multicolumn{3}{|c|}{$\begin{array}{l}\text { During sleep (\% of time when } \\
\text { oxygen saturation could not be } \\
\text { analysed) }\end{array}$} & \multirow{2}{*}{$\begin{array}{l}\text { No with arterial } \\
\text { oxygen } \\
\text { saturation }<80 \% \\
\text { for } 3-50 \mathrm{~min}\end{array}$} & \multirow{2}{*}{$\begin{array}{c}\text { No with arterial } \\
\text { oxygen } \\
\text { saturation }<80 \% \\
\text { and } \\
\text { with periodic } \\
\text { breathing }\end{array}$} \\
\hline & & & Total & $\begin{array}{l}\text { Active } \\
\text { sleep }\end{array}$ & $\begin{array}{l}\text { Quiet } \\
\text { sleep }\end{array}$ & & \\
\hline 3 weeks & 168 & 8 (5.5 to 14$)$ & 41 & 61 & 31 & 10 & 4 \\
\hline 3 months & 167 & 10.2 (7 to 13.5$)$ & 27 & 58 & 21 & 4 & 1 \\
\hline
\end{tabular}


5 Andersson D, Sjostrom A, Gennser G, Johnson P. The effect of hypoxia and hyperoxia on breathing and ventilation in newborn infants. In: Jones CT, ed. Physiological development of the fetus and neomate. New York, Ithaca: Perinatology Press, 1988:651-6.

\section{Public must be warned of weak evidence} for risk of serious harm

EDITOR-The public look to doctors for an evaluation of evidence and for advice. Parkins et al found that infants experience hypoxia when they are exposed to $15 \%$ oxygen. ${ }^{1}$ Milner commented in his editorial that all the epidemiological evidence indicates that flying is safe for healthy children in the first year of life. ${ }^{2}$ This claim is based on the reassurance given by a representative from British Airways, who said that the company would have investigated any incident.

There is some limited physiological evidence that a risk exists, but no epidemiological evidence. The public should be informed early of weak evidence that indicates a risk of serious harm but it should also be informed of the limitations of that evidence. This is consonant with public outrage at the withholding of early evidence that bovine spongiform encephalopathy presents a risk to humans.

More research is needed, but we also need discussion of how to evaluate the strength, quality, and relevance of evidence and how to translate these into practical advice for the public. Doctors, guided by experts in reviewing research, should judge whether advice along the following lines is justified.

"Some research suggests that there may be an increased chance of infants dying during and in the first few days after a long airline flight. However, this evidence is weak. It is not strong enough to make a recommendation that infants should not fly. Airline travel may be as safe for infants as it is for adults, but further research is necessary to clarify this. In the meantime, it would be prudent that if parents do choose to fly with a child under 1, they should be careful with sedatives and when children have colds."

Even weak evidence can make a difference. My wife, who is an anaesthetist, and I recently flew with our 9 month old daughter. We sedated her with a low dose of trimeprazine $(2 \mathrm{mg} / \mathrm{kg})$, a commonly used sedative. At one point she stopped breathing and experienced altered consciousness for around 30 seconds. My wife was about to start oxygen treatment when the child improved with stimulation. We would not fly again with a child who is under 1 unless it was important. After reflection on Parkins et al's findings and our experience we would not use sedatives again. Like most people, we are averse to loss.

Julian Savulescu Associate professor

Centre for Human Bioethics, Monash University, Melbourne, Australia 3168

1 Parkins KJ, Poets CF, O’Brien LM, Stebbens VA, Southall DP. Effect of exposure to $15 \%$ oxygen on breathing patterns and oxygen saturation in infants: interventional study. [With commentaries by J Savulescu and V Hughes and authors' reply.] BMJ 1998;316:887-94. (21 March.)

2 Milner AD. Effects of $15 \%$ oxygen on breathing patterns and oxygenation in infants BMJ 1998;316:873. (21 March.)
Risks associated with hypoxia during flights need to be investigated

EDITOR-Milner's editorial, ${ }^{1}$ which accompanies Parkins et al's study, ${ }^{2}$ states that flying is probably safe for infants. Because of birth events, however, not all people are born equal, and magnetic resonance imaging of children who develop seemingly normally after hypoxic-ischaemic encephalopathy at birth shows that their brains are not normal. ${ }^{2}$ Magnetic resonance imaging is likely to show similar morbidity in some children after seemingly uncomplicated deliveries and may provide crucial information in cot deaths. Immaturity of the blood-brain barrier and persisting oedema in the ischaemic penumbra in the midbrain may be adversely affected by the acute hypoxia in aircraft at cruising altitude, especially when exposure is maintained for many hours on long haul flights. The minimum oxygen content allowed in the workplace at sea level by the British Health and Safety Executive is $18 \%$. Parkins et al calculated that the partial pressure of oxygen at the cabin "altitude" of commercial aircraft is equivalent to breathing $15 \%$ at sea level, but the work of breathing is much greater at sea level than at altitude because of the greater density of $15 \%$ oxygen in nitrogen. A small reduction in haemoglobin saturation reflects a much greater fall in the plasma oxygen tension, which alone determines the transport of oxygen into tissues. When haemoglobin saturation is reduced from $95 \%$ to $80 \%$, the plasma oxygen tension falls from $12.6 \mathrm{kPa}$ at sea level to about $6.6 \mathrm{kPa}-\mathrm{a}$ reduction of $47 \%$. Hypoxia during flying may be associated with angina, stroke, and an increased risk of deep vein thrombosis. The symptoms may be delayed because these conditions may take hours or days to develop, which allows the relevance of the flight to be disputed.

The infants in the study were exposed to hypoxia for only six hours, but many flights last for over 12 hours. The current maximum cabin altitude for commercial aircraft of 2438 metres derives from the introduction of the jet engine and cabin pressurisation when flight durations were limited. Although living at high altitude is associated with an increased capillary density in the brain and other organs, this acclimatisation to hypoxia takes several weeks.

There is a trend in aircraft manufacture to use a higher cabin altitude, ${ }^{5}$ and fligh durations of over 12 hours are common. The upper limit of 2438 metres, established many years ago, needs to be revised. The risks that are associated with the hypoxia that some newborn infants and adults experience while flying need to be investigated.

P B James Senior lecturer in occupational medicine Wolfson Hyperbaric Medicine Unit, University of Dundee, Ninewells Hospital and Medical School, Dundee DD1 9SY

1 Milner AD. Effects of $15 \%$ oxygen on breathing pattern and oxygenation in infants. BMJ 1998;316:873. (21 March.) 2 Parkins KJ, Poets CF, O'Brien LM, Stebbens VA, Southal DP. Effect of exposure to $15 \%$ oxygen on breathing patterns and oxygen saturation in infants: interventional study. [With commentaries by J Savulescu and V Hughes and authors' reply.] BMJ 1998;316:887-94. (21 March.) 3 Rutherford M, Pennock J, Schwieso J, Cowan F, Dubowitz L. Hypoxic-ischemic encephalopathy: early and late magnetic resonance imaging findings in relation to outcome. Arch Dis Child 1996;75:F145-51.

4 Harik SI, Behmand RA, LaManna JC. Hypoxia increases glucose transport across the blood-brain barrier. J Appl Physiol 1994;77:896-901.

5 Cottrell JJ. Altitude exposures during aircraft flight: flying higher. Chest 1986;92:82-4

\section{Authors' reply}

EDitor-The sudden infant death syndrome is the commonest cause of infant death in developed countries. It is therefore important to understand the mechanisms responsible. West states correctly that our research was non-therapeutic. It did, however, conform to guidelines set by the local research ethics committee, and the risks involved were minimal.

We believe that most parents do not understand the hypoxic effects of air travel or visiting high altitude. Our previous research had shown a possible link between airway hypoxia, particularly during respiratory infection, and sudden infant death. We think that our approach is the most ethical and appropriate way of investigating the concerns we had raised.

We were aware that our cut off point of oxygen saturation ( $80 \%$ for 60 seconds) was the mean lowest value documented during sleep in healthy infants living at high altitude. ${ }^{1}$ Hypoxic challenge ended prematurely in a minority of our sample, which suggests that this response is uncommon in healthy infants living at sea level.

Johnson et al's measurements of oxygen saturation are 5-6\% lower than our reference values; their observation that healthy infants can have saturation values of $<80 \%$ is to be expected and does not contradict our protocol. The terminology in our article ("severe and prolonged desaturation") related only to the context of our research design and did not reflect a clinical indication of concern. This may have influenced Pace to believe that clinically relevant hypoxaemia was present in four of our babies during the study. In the context of anaesthesia, where children are sedated and breathing additional inspired oxygen, saturations of $80 \%$ would of course indicate a clinical problem. In the context of our study they represent a variability in responses to a physiological challenge that babies undergo daily, either in air travel, living, or visiting at high altitude.

Niermeyer et al did not report on apparent life threatening events. ${ }^{1}$ They described cyanotic episodes during feeding and sleep, and commented on deaths from airway hypoxia. Heath reported on 15 infants who died 2.1 months after moving to high altitude. ${ }^{2}$ Data from Sui et $\mathrm{al}^{3}$ are also cited by Niermeyer and Moore. Increased muscle in pulmonary arterioles has been reported in infants who died of the sudden infant death syndrome. ${ }^{4}$ Bronchiolitis is commonly identified at postmortem examination in infants who have died suddenly and unexpectedly. ${ }^{5}$ 
We are unaware of data that suggest that our experimental groups-healthy infants and siblings of victims of the sudden infant death syndrome-are at increased risk of "abnormal oxygen transport, pulmonary function, and control of breathing." Mechanisms for airway hypoxia that trigger sudden death in infants potentially include changes in the pulmonary vasculature and the smooth muscle in the peripheral airways of the lung. We were careful not to imply that we had found an explanation for the syndrome.

Pace thinks that our study should have been conducted on an aircraft. This incorrectly assumes that we were primarily interested in the effects of air travel. We agree with Platt et al that provocation in the media of fear about the safety of air travel for babies was inappropriate and premature. We appreciate their epidemiological data but question whether sample size was sufficient to discount a relation between air travel and sudden infant death. We have now received letters from parents and doctors that identify 10 infants who have died within a few days after an airline flight. We were also informed about four infants who had experienced apparent life threatening events, one of whom required cardiopulmonary resuscitation on the plane. One of these died shortly after the plane landed.

Johnson et al think that our study should have conformed to published guidelines before we concluded that responses to hypoxia were unpredictable. Their own guidelines do not, however, seem relevant to our model. They have misunderstood our analysis, which was not restricted to periods of regular pattern breathing.

We agree with Savulescu that research should be publicly available. We aimed to elucidate responses to airway hypoxia in infants who normally breathe $21 \%$ oxygen. Our findings and the subsequent correspondence justify further investigation. Safety of air travel safety for babies can probably best be determined by observations during and after flights.

David Southall Professor

C Poets Lecturer in paediatrics

Louise O'Brien Research assistant

Valerie Stebbens Research assistant

K Parkins Research fellow

Directorate of Child Health, Department of

Academic Paediatrics, North Staffordshire Hospital, Stoke-on-Trent, Staffordshire ST4 6QG

1 Niermeyer S, Shaffer EM, Thilo E, Corbin C, Moore LG. Arterial oxygenation and pulmonary arterial pressure in healthy neonates and infants at high altitude. J Pediatr 1993;123:767-72.

2 Heath D. Missing link from Tibet. Thorax 1989;44:981-3.

3 Sui GJ, Liu YH, Cheng XS, Anand AS, Harris E, Harris P, et al. Subacute infantile mountain sickness. J Pathol 1988;155:161-70.

4 Williams A, Vawter G, Reid L. Increased muscularity of the pulmonary circulation in victims of sudden infant death syndrome. Pediatrics 1979;63:18-23.

5 Downham MAPS, Gardner PS, McQuillin J, Ferris JAJ Role of respiratory viruses in childhood mortality; $B M J$ 1975;i:235-9.

\section{Ecological studies are a poor means of testing aetiological hypotheses}

EDITOR-The declines in cardiovascular diseases in Poland, "apparently without precedent in peacetime," are similar to the declines seen in Britain over the same period. ${ }^{2}$ The table shows secular declines in mortality from cardiovascular diseases in Britain: between 1991 and 1994, death rates from both ischaemic heart disease and stroke fell dramatically, particularly among men at all ages and women aged over 55 years. In Britain these death rates are continuing to fall, in contrast to Poland. Furthermore, as mortality from ischaemic heart disease in Britain plateaued between 1980 and 1985 and then fell, the declines observed between 1985 and 1989 were as striking as those in Poland: $18.5 \%$ and $15 \%$ for men and women aged 55-64 years respectively, compared with Polish declines between 1991 and 1994 of $20 \%$ and $16 \%$ for men and women aged 45-64 years respectively. In contrast, mortality from stroke in Poland did not fall nearly so much as in Britain: $4 \%$ for men and no change in women. Over such a short time, these trends are unlikely to be due to artefacts of coding or practice of certification in either country.

It is probable that a lag will occur between secular trends in disease rates and changes in any explanatory risk factors. In Poland consumption of animal fats fell and consumption of vegetable fats and fruit rose at the same time as mortality declined, making these dietary intakes less plausible explanatory factors. In Britain mortality from ischaemic heart disease has been falling since the 1980s, suggesting that explanatory changes in risk factors must have been occurring before this time. Between 1950 and 1980, personal consumption of total fats fell by only $3 \%$ and consumption of fresh fruit increased by $45 \%$; more striking was the 19 -fold increase in consumption of poultry. Social and economic changes were also marked during this period: the rate of car ownership increased almost fourfold, and unemployment rose 4.5-fold. ${ }^{3}$ From this evidence, it is unlikely that anyone would conclude that increase in poultry consumption or rising unemployment explained falls in rates of heart disease.

Ecological analyses are a weak means of testing aetiological hypotheses, and only limited inferences can be made about concurrent (or lagged) changes in possible risk factors. Using individual data on risk factors and clinical events, it is probable that

Percentage reduction in mortality from cardiovascular diseases in Britain between 1991 and 1994

\begin{tabular}{lcccccc}
\multirow{2}{*}{ Age groups (years) } & \multicolumn{2}{c}{$\begin{array}{c}\text { Ischaemic heart disease } \\
\text { (ICD codes }\end{array}$} & & & \multicolumn{2}{c}{ Stro-414) } \\
\cline { 2 - 3 } \cline { 5 - 6 } & Men & Women & & Men & Women \\
\hline $45-54$ & 22 & 3 & & 17 & 5 \\
\hline $55-64$ & 17 & 21 & & 19 & 17 \\
\hline $65-74$ & 12 & 8 & & 18 & 14 \\
\hline
\end{tabular}

about half of the declining secular trend may be explained by concomitant falls in major risk factors for cardiovascular disease (that is, blood pressure, smoking, and blood cholesterol). ${ }^{4}$ It is also likely that trends in both risk factors and mortality are due to social and economic factors that operate at a population, rather than individual, level and also due to the lagged effects of such socioeconomic change. The contributions of specific risk factors to secular trends in cardiovascular disease are likely to vary between countries and time periods, and be affected by the proportion of the population exposed, making causal inferences of general applicability difficult.

Shah Ebrahim Professor of clinical epidemiology Royal Free Hospital School of Medicine, University George Davey Smith Professor of clinical epidemiology

Department of Social Medicine, University of Bristol, Bristol BS 2PR

1 Zatonski WA, McMichael AJ, Powles JW. Ecological study of reasons for the sharp decline in mortality from ischaemic heart disease in Poland since 1991. BMJ 1998;316:104751. (4 April.) G. Cardiovascular diseases. In: Murphy M, Charlton J, eds. The health of adult Britain 1841-1994. Vol 2. London: Stationery Office, 1997:60-81.

3 Charlton J, Murphy M, eds. The health of adult Britain 1841 1994. Vol 1. London: Stationery Office, 1997.

4 Hunink MG, Goldman L, Tosteson AN, Mittleman MA, Goldman PA, Williams LW, et al. The recent decline in mortality from coronary heart disease, 1980-1990. The effect of secular trends in risk factors and treatment. JAMA 1997;277:535-42

5 Davey Smith G, Egger M. Understanding it all: metatheories and mortality trends. BMJ 1996;313:1584-5.

\section{Studies must establish whether prolonged QTc interval in newly diagnosed type 1 diabetes is reversible}

EDITOR-Naas et al found that the corrected QT (QTc) interval, QT dispersion, and QTc dispersion are accurate predictors of cardiac death in newly diagnosed non-insulin dependent diabetes. ${ }^{1}$ QT interval is influenced by many factors, including electrolyte abnormalities, myocardial ischaemia, autonomic imbalance, and alcohol toxicity. Prolongation of the QT interval is related to the severity of autonomic neuropathy in patients with alcoholic and non-alcoholic liver disease. ${ }^{2}$

We studied 27 patients with newly diagnosed insulin dependent diabetes (mean (SD) age 23 (7); 17 men, 10 women). Autonomic function was evaluated by five standard cardiovascular tests, ${ }^{3}$ and the QTc interval was determined with Bazett's formula. Two patients had two abnormal variables, and five had one abnormal result College London Medical School, London NW3 2PF

2 Charlton J, Murphy M, Khaw K-T, Ebrahim S, Davey Smith 
of a reflex test. In 20 patients all five tests gave normal results. The heart rate response to deep breathing was abnormal in two patients; the result of a sustained handgrip test was abnormal in four; postural hypotension was observed in one. All values of the Valsalva ratio were normal.

The QTc interval was longer in patients with at least one abnormal result of an autonomic test than in patients with normal results (mean 435 (17) ms v 393 (27) ms; $\mathrm{P}<0.001$, Student's $t$ test). No difference was found between QTc values among patients with one and two abnormal results of reflex tests (434 (18) $\mathrm{ms}$ and 438 (13) $\mathrm{ms}$ respectively). A prolonged QTc interval (>440 ms) was more common in patients with at least one abnormal result of a cardiovascular test than in patients with normal results $\left(3 / 7 v 0 / 20\right.$ patients; $\mathrm{P}<0.01 \chi^{2}$ test). When the five tests of reflex variables were analysed separately, the only one that showed a significant correlation with QTC lengthening was the sustained handgrip test $(r=-0.38, \mathrm{P}=0.05)$; this is in accordance with data suggesting that sympathetic dysfunction has a role in the development of QTc prolongation.

Our data provide evidence of a relation between autonomic imbalance and prolongation of the QT interval in newly diagnosed insulin dependent diabetes. We agree with Naas et al that analysis of the QT interval could be used for screening purposes in newly diagnosed diabetic patients. We would also suggest, however, that in patients with a prolonged QTc interval even standard autonomic reflex tests should be performed, as well as more extensive cardiac investigations.

Peter Kempler* Associate professor

Katalin Keresztes Clinical doctor

Zsolt Hermányi Clinical doctor

Anna Marton Clinical doctor

I Department of Medicine, Semmelweis University, , Budapest, H-1083 Hungary

*The authors were supported by the National Research Fund, Ministry of Welfare, and Zsigmond Diabetes Foundation.

1 Naas AAO, Davidson NC, Thompson C, Cummings F, Ogston SA, Jung RT, et al. QT and QTc dispersion are grton SA, Jurg kT, en accurate predictors of cardic death in newly diagnosed non-insulin dependent diabetes:

2 Kempler P, Váradi A, Szalay F. Autonomic neuropathy and prolongation of QT-interval in liver disease. Lance 992;340:318

3 Ewing DJ, Clarke BF. Diagnosis and management of

diabetic autonomic neuropathy. BMJ 1982;285:916-8.

\section{Helicobacter pylori and surgery}

\section{Bile reflux is important in eradicating Helicobacter pylori}

EDITOR-Danesh et al reviewed data regarding the incidence of Helicobacter pylori in patients who had undergone vagotomy for peptic ulcer disease. ${ }^{1}$ Our prospective study from 1996 on the same subject was, however, not included in the analysis.

Fifty four patients who had had a vagotomy for duodenal ulcer disease and 50 patients with duodenal ulcer disease who had not had an operation had an endoscopy, and $H$ pylori status was determined.
$H$ pylori was detected in $94 \%$ of those who had not had an operation, but in only 52\% of those who had had a vagotomy.

We found significant differences in $H$ pylori infection in the group who had had a vagotomy, however, depending on the exact procedure performed. Altogether $61 \%$ of patients who had had pyloroplasty were positive for $H$ pylori, compared with only $25 \%$ of those who had had gastroenterostomy and all of those treated by highly selective vagotomy. We reached the same conclusion as Danesh et al and suggested that duodenogastric reflux of bile was important in eradicating the organism and therefore procedures associated with significant bile reflux, such as gastroenterostomy, resulted in lowest colonisation rates by H pylori.

Danesh et al showed a higher overall prevalence of $H$ pylori after vagotomy $(83 \%)$ than we did, but most of the data concerned were collected after highly selective vagotomy, which is associated with no increase in bile reflux, and we found $H$ pylor in all such patients in this group. Therefore the conclusion of Danesh et al that vagotomy is associated with a high prevalence of $H$ pylori does not hold true for all patients who have had a vagotomy but only a subgroup of patients who had had a highly selective vagotomy. We believe that this may partly explain the poor results in terms of curing duodenal ulcer disease associated with highly selective vagotomy as most of the patients continued to harbour $H$ pylori, which led to recurrent ulceration.

In the group of patients who had had a partial gastrectomy, one reason for remission of $H$ pylori was resection of the distal gastric tissue and another reason must again be bile reflux in the remnant stomach. This will depend on the reconstruction method that was used, and Danesh et al did not have sufficient details from their review to specify this.

The most important finding from our study was that all patients with recurrent duodenal ulcer disease after vagotomy were positive for $\mathrm{H}$ pylori. We therefore agree with Danesh et al that there is a case for prescribing eradication treatment to this group of patients if they have symptoms.

D Karat Specialist registrar in surgery

S M Griffin Consultant surgical gastroenterologist Northern Oesophagogastric Unit, Royal Victoria Infirmary, Newcastle upon Tyne NE1 4LP

$$
\begin{aligned}
& 1 \text { Danesh J, Appleby P, Peto R. How often does surgery for } \\
& \text { peptic ulceration eradicate Helicobacter pylori? Systematic } \\
& \text { review of } 36 \text { studies. BMJ 1998;316:746-7. (7 March.) } \\
& 2 \text { Karat D, O'Hanlon DM, Biggin C, Hayes N, Griffin SM. } \\
& \text { Incidence of Helicobacter pylori after vagotomy for DU } \\
& \text { disease is dependent on the drainage procedure } \\
& \text { performed. BrJ Surg 1996;83:28. }
\end{aligned}
$$

\section{Helicobacter pylori is merely suppressed} by bile

EDITOR-Danesh et al say that the prevalence of Helicobacter pylori falls to 50\% (95\% confidence interval $45 \%$ to $56 \%$ ) after partial gastrectomy. ${ }^{1}$ They believe that this is a true reflection of eradiaction of $H$ pylori and quote an article from 1986 that suggests that bactericidal effects of bile reflux may be, at least in part, responsible. ${ }^{2}$ An article in 1989 showed that after Roux-en-Y reconstruction in patients who had previously had a partial gastrectomy the prevalence of $H$ pylori rose from $54 \%$ (similar to the figure quoted by Danesh et al) to $92 \%$ after biliary diversion. This indicates that $H$ pylori is merely being suppressed by bile and is colonising other parts of the stomach such as the gastric fundus. It does not support the assumption that partial gastrectomy or the resulting bile reflux produce true eradication of $H$ pylori in almost half of subjects.

S Khulusi Senior registrar

Royal Liverpool University Hospital, Liverpool L7 8XP.

1 Danesh J, Appleby P, Peto R. How often does surgery for peptic ulceration eradicate Helicobacter pylori? System review of 36 studies. BMJ 1998; 316:746-7. (7 March.) 2 O'Connor HJ, Dixon MF, Wyatt JI, Axon AT, Ward DC, Dewar EP, et al. Effect of duodenal ulcer surgery and enterogastric reflux on Campylobacter pyloridis. Lancet 1986;ii:1178-81

3 O'Connor HJ, Newbold KM, Alexander WJ, Thompson H, Drumm J, Donovan IA. Effect of Roux-en-Y biliary diversion on Campylobacter pylori. Gastroenterology 1989;97:958-64.

\section{Role of bile reflux is insufficiently explained}

EDITOR-In their systematic review Danesh et al looked at peptic ulcer surgery and eradication rates of Helicobacter pylori. Although we agree that bile acid reflux may contribute to the success of partial gastrectomy in eradicating $\mathrm{H}$ pylori, we believe that their analysis is flawed in two respects.

Firstly, although highly selective vagotomy preserves the function of the pylorus, truncal vagotomy requires either a pyloroplasty or gastroenterostomy, both of which are associated with gastric bile acid reflux. Secondly, patients undergoing surgery often receive prophylactic antibiotics that commonly include metronidazole. Patients who have had a partial gastrectomy or pyloroplasty are more likely to receive these antibiotics than those undergoing highly selective vagotomy.

The observation of Danesh et al might be explained by the fact that prophylactic antibiotics may kill any $H$ pylori organism present. As there are patients with bile reflux in both groups, however, it is difficult to draw any particular conclusion from their work.

T D Heymann Consultant physician and gastroenterologist

Peter D Willson Consultant general and gastrointestinal surgeon

Kingston Hospital, Kingston upon Thames, Surrey KT2 7QB

1 Danesh J, Appleby P, Peto R. How often does surgery for peptic ulceration eradicate Helicobacter pylori? System

\section{Authors should not extrapolate findings into unresearched areas}

EDITOR-One of the pillars of evidence based medicine is the systematic review. It is easy for the authors of systematic reviews, however, to extend the results of their study into areas which have not been evaluated. Danesh et al examined how often surgery 
for peptic ulcer disease eradicated Helicobacter pylori. ${ }^{1}$ They found that $H$ pylori is eradicated infrequently (eradication rate $50 \%$ after partial gastrectomy, $17 \%$ after vagotomy). They then extended their recommendations into an area that they had not examined and suggested that clinicians should review patients who have had previous gastric surgery for ulcer disease and consider treatment with antibiotics.

Most patients who have had surgery for ulcers are elderly since surgery for peptic ulcer is now rarely done. These patients will have had $H$ pylori for much of their lives. Whether or not eradication treatment will be beneficial to them is unknown. This is not the subject of the review by Danesh et al, and they should not have made that recommendation. The limited evidence available suggests that the mucosal changes which are present with longstanding $H$ pylori infection are not removed by eradication treatment. ${ }^{2}$ Patients with a recurrent ulcer should receive eradication treatment, but this is not mentioned in the recommendation by Danesh et al. Although potential complications-for example, pseudomembranous colitis-are rare, caution is necessary before treatment with antibiotics is initiated in the absence of a proved benefit. ${ }^{3}$

Authors of systematic reviews must be careful not to extrapolate their conclusions into unresearched areas. To do so risks bringing systematic reviews into disrepute.

D G Colin-Jones Consultant gastroenterologist C D Roseveare Specialist registrar, gastroenterology Department of Medicine and Gastroenterology, Queen Alexandra Hospital, Portsmouth PO6 3LY

1 Danesh J, Appleby P, Peto R. How often does surgery for peptic ulceration eradicate Helicobacter pylori? Systematic review of 36 studies. BMJ 1998:316;746-7. (7 March.)

2 Maconi G, Lazzaroni M, Sangaletti O, Bargiggia S, Vago I Porro GB. Effect of Helicobacter pylori eradication on gastric histology, serum gastrin and pepsinogen I levels and gastric emptying in patients with gastric ulcer. Am J Gastroenterol 1997;92:1844-8.

3 Roseveare C, van Heel DA, Arthur MJP. Helicobacter pylori:beware "blind" eradication. Gut 1998;42:757.

\section{Authors' reply}

EdITOR-Our review of Helicobacter pylori status in 1150 patients from 36 studies after gastric surgery for peptic ulceration indicated a substantially higher prevalence of the infection after vagotomy than after partial gastrectomy $(83 \% v 50 \%)$, and the additional data on 54 patients who had had a vagotomy from Karat and Griffin leave these numerical conclusions largely unchanged.

We accept their emphasis, however, that effects of different types of surgical procedure must be considered separately. The mean interval between surgery and testing for $H$ pylori in the studies we reviewed was about 10 years, and testing usually entailed histology of gastric samples taken from several different sites. This makes it implausible that $H$ pylor $i$ was merely suppressed rather than killed in most samples where it was not detected. It is also implausible that antibiotic prophylaxis at the time of surgery might have been responsible for killing the bacteria, as substantial eradication rates can- not at present be achieved without at least a week of treatment with a regimen that includes at least two oral antibiotics in high doses (plus an antisecretory agent). ${ }^{1}$ With such intensive antibiotic regimens, however, permanent eradication of $H$ pylori would often be possible, and should sometimes be helpful since relapses of peptic ulceration may continue to occur even several years after gastric surgery.

John Danesh Rhodes scholar

Richard Peto Professor

Clinical Trial Service Unit and Epidemiological Studies Unit, University of Oxford, Radcliffe Infirmary, Oxford OX2 6HE

1 Walsh JH, Peterson WL. The treatment of Helicobacter pylori infection in the management of peptic ulcer disease. N Engl J Med 1995;333:984-91.

\section{Relation between birth weight and blood pressure is independent of maternal blood pressure}

EDITOR-Walker et al conclude that the now well established inverse association between birth weight and blood pressure may in part be explained by hereditary factors. ${ }^{1}$ They suggest that low birth weight is a feature of an inherited predisposition to hypertension, perhaps because it is associated with higher maternal blood pressure during pregnancy.

We have examined the influence of maternal blood pressure during pregnancy on the association between birth weight and blood pressure in a study of 8-11 year old children in 10 British towns. ${ }^{23}$ Detailed antenatal and birth records were located for 1573 singleton children born in the town in which blood pressure was later measured 1494 included blood pressure measurements during pregnancy. Although maternal systolic blood pressures at both 28 weeks' and 36 weeks' gestation were correlated with childhood systolic pressure at 8-11 years (correlation coefficients 0.16 and 0.14 respectively; $\mathrm{P}<0.0001$ ), neither measure was correlated with birth weight (correlation coefficients 0.01).

We also examined the effect of adjustment for maternal blood pressure on the relation between birth weight and blood pressure (table). Results are presented for the sexes together and for girls alone because we previously noted that the association between birth weight and blood pressure was concentrated among girls and only weakly present among boys at this age." Adjustment for maternal blood pressure at
36 weeks' gestation did not influence the size or the significance of the association between birth weight and blood pressure, either for all children or for girls alone. Similar results were seen after adjustment for antenatal blood pressure at 12, 18, and 28 weeks (data not shown).

There is no doubt that in severe maternal hypertension in pregnancy the birth weight of the child is reduced. ${ }^{4}$ Our data suggest that there is little or no association between maternal blood pressure and birth weight in the general population and that, at least in children, the relation between birth weight and blood pressure is strongly independent of maternal blood pressure.

Stephanie J C Taylor Honorary research fellow Katherine Hird Clinical research fellow

Peter Whincup Reader in clinical epidemiology

Department of Primary Care and Population

Sciences, Royal Free Hospital School of Medicine, London NW3 2PF

Derek Cook Reader in epidemiology

Department of Public Health Sciences, St George's Hospital Medical School, London SW17 0RE

1 Walker BR, McConnachie A, Noon JP, Webb DJ, Watt CM. Contribution of parental blood pressures to association between birth weight and adult high blood pressure: cros sectional survey. BMJ 1998;316:834-7. (14 March.)

2 Taylor SJC, Whincup PH, Cook DG, Papacosta O, Walker M. Size at birth and blood pressure: cross sectional study in 8-11 year old children. BMJ 1997;314:475-80.

3 Taylor SJC, Whincup PH, Cook DG, Papacosta O. Blood pressure in pregnancy and fetal growth. Lancet 1997; 349:802.

4 McCowan LME, Buist RG, North RA, Gamble G. Perinata morbidity in chronic hypertension. Br J Obstet Gymacol 1996;103:123-9.

\section{Screening for Chlamydia trachomatis}

\section{New methods are needed to assess the} burden of illness from chlamydia

EDITOR-Boag and Kelly's editorial is a useful review of some of the issues raised in the recently published summary of the findings of the chief medical officer's expert advisory group on genital chlamydial infection. ${ }^{1}$ If successfully implemented, these recommendations would be one of the most important public health interventions in controlling communicable diseases of the past 25 years. However, they do not address the issue of how the proposed screening programme might be evaluated.

Boag and Kelly imply that successful intervention would reduce the incidence of infertility. Although this may be true, monitoring rates of infertility is unlikely to provide a reliable or timely measure of the

Associations between birth weight and systolic blood pressure summarised as regression coefficients, showing effect of adding maternal blood pressure at 36 weeks' gestation to multiple regression model ${ }^{*}$

\begin{tabular}{lccccccc} 
& \multicolumn{2}{c}{$\begin{array}{c}\text { Without maternal blood pressure in multiple } \\
\text { regression model }\end{array}$} & & \multicolumn{2}{c}{$\begin{array}{c}\text { With maternal blood pressure in multiple } \\
\text { regression model }\end{array}$} \\
\cline { 2 - 3 } & $\begin{array}{c}\text { Regression } \\
\text { coefficient } \\
(\mathbf{m m ~ H g} / \mathbf{k g})\end{array}$ & SE & P value & & $\begin{array}{c}\text { Regression } \\
\text { coefficient } \\
(\mathbf{m m ~ H g} / \mathbf{k g})\end{array}$ & SE & P value \\
\hline All children $(\mathrm{n}=1494)$ & -1.24 & 0.59 & 0.02 & & -1.20 & 0.55 & 0.03 \\
\hline Girls only $(\mathrm{n}=696)$ & -2.31 & 0.85 & 0.007 & & -2.27 & 0.85 & 0.006 \\
\hline
\end{tabular}

${ }^{*}$ All multiple regression models were simultaneously adjusted for age, sex, height, and current ponderal index. 
true impact of intervention. Firstly, genital chlamydial infection is associated with only about $75 \%$ of cases of tubal factor infertility, which in turn is thought to account for only $36 \%$ of all cases of infertility. ${ }^{2}$ Secondly, the highest prevalence of genital chlamydial infection is seen in women aged 16 to 19 , but more women are becoming pregnant later in life. ${ }^{4}$ Women are thus likely to seek advice about infertility many years, perhaps even decades, after infection. Thirdly, other factors such as expectations of the success of treatment might influence the number of women seeking infertility treatment.

Boag and Kelly also imply that the promised pilot studies would show whether reductions in morbidity could be achieved through intervention. This is unlikely to be the case until new measures are developed for monitoring the burden of illness associated with chlamydial infection, particularly pelvic inflammatory disease, which accounts for much of the illness associated with this infection. Although the prevalence of chlamydial infection may be reduced in the short term by screening, this would not necessarily reflect a corresponding decrease in pelvic inflammatory disease. Short term reductions in prevalence may be associated with reduced duration of infection rather than reduced incidence of disease.

Monitoring trends in pelvic inflammatory disease will require large investment in the development of suitable, widely applicable diagnostic tools and surveillance systems. Only through the development of such systems will the effectiveness of genital chlamydial screening be able to be assessed. This is one of the main challenges if the proposals embodied in the expert advisory group's report are to be realised.

I Simms Senior scientist (epidemiology)

G Hughes Principal scientist (epidemiology) M Catchpole Consultant epidemiologist HIV and Sexually Transmitted Diseases Division, Public Health Laboratory Service Communicable Disease Surveillance Centre, London NW9 5EQ

1 Boag F, Kelly F. Screening for Chlamydia trachomatis. BMJ 1998;316:1474. (16 May.)

2 Cates W, Fairley TMM, Rowe PJ. Worldwide patterns of infertility: is Africa different? Lancet 1985;i:596.

3 Lindsay DT, Trounson AO, Andersen AN. Female infertility: causes and treatment. Lancet 1994;343:1539-44.

4 Simms I, Hughes G, Swan AV, Rogers PA, Catchpole M. New cases of genitourinary medicine clinics: England 1996. Communicable Disease Report Supplement 1998:8. S1-11.

\section{Genitourinary medicine clinics in} Scotland give high priority to contact tracing

EDITOR-In their editorial Boag and Kelly imply that contact tracing for chlamydia currently does not receive high priority in genitourinary medicine clinics. ${ }^{1}$ If that is the case in their hospital, the Chelsea and Westminster Hospital, London (and Clarke's recent review suggests that this may be so for some clinics in London ${ }^{2}$ ), I do not think it is representative of the United Kingdom as a whole. The document Clinical Guidelines and Standards for the Management of Uncomplicated Genital Chlamydial Infection published in November last year by the Central Audit Group in Genitourinary Medicine states quite clearly that partner notification must be undertaken in all cases. ${ }^{3}$

Contact action figures for chlamydial and gonococcal infections in genitourinary medicine clinics in Scotland are published annually. The most recent data (for 1996-7) show that 896 contacts were sought from a total of 1856 index episodes of chlamydial infection, of whom $553(62 \%)$ were subsequently seen at a genitourinary medicine clinic. The proportion of contacts sought (48\% of index cases) was identical with that for gonococcal infections, for which 193 contacts were sought from a total of 397 index episodes, of whom $127(66 \%)$ subsequently attended a genitourinary medicine clinic. These figures support the fact that partner notification for chlamydial infections in Scottish genitourinary medicine clinics is given as high a priority as that for gonococcal infections.

I agree with Boag and Kelly that partner notification outwith genitourinary medicine clinics and their integral health adviser network is currently not given high priority and that the success of a national screening programme would depend on the effectiveness of this aspect of patient management. Close collaboration between genitourinary medicine clinics, local primary care, and the laboratory services in rapidly communicating positive results will facilitate the contact tracing process and help control this silent epidemic.

C Thompson Consultant in genitourinary medicine Victoria Hospital, Kirkcaldy, Fife KY2 5AH

\footnotetext{
Boag F, Kelly F. Screening for Chlamydia trachomatis. $B M$ 1998:316:1474.(16 May)

2 Clarke J. Contact tracing for chlamydia: data on Clarke J. Contact tracing for chlamy
effectiveness. Int J STD AIDS 1998;9:187-91.

3 Central Audit Group in Genitourinary Medicine. Clinical 3 Central Audit Group in Genitourinary Medicine. Clinical genital chlamydial infection. London: Royal College of Physicians, 1997.

4 Information and Statistics Division, National Health Serv ice in Scotland. Genitourinary Medicine Statistics, Scotland. Year ending 31 March 1997. Edinburgh: ISD, 1998.
}

\section{Contacts attendance rate is $70 \%$ in Hertfordshire}

EDITOR-We were surprised to read in the editorial by Boag and Kelly and elsewhere in the $B M J$ that contact tracing for Chlamydia trachomatis infection does not currently receive high priority, even in genitourinary medicine clinics. ${ }^{12}$ We strongly believe that it is an essential part of managing sexually transmitted infections alongside medical management. $C$ trachomatis infection is the most prevalent treatable sexually transmitted infection in the United Kingdom. Its sequelae-pelvic inflammatory disease, chronic pelvic pain, infertility, and ectopic pregnancy in women - are well known. It can cause epididymitis, recurrent or persistent urethritis, and chronic prostatitis. However, the infection may remain asymptomatic

As it is a sexually transmitted infection, treating one partner is of little benefit in controlling the infection. Genitourinary medicine clinics are well placed to undertake contact tracing (partner notification) as it is already built into their work programme. Contact tracing for chlamydia is taken seriously in our clinics at this hospital and at Lister Hospital, Stevenage. The service at Hertford started in 1990 and is part time, offering three clinic sessions a week, and the service at Lister Hospital was also, until recently, part time with three clinic sessions a week. We looked at all cases of chlamydial infection from 1990 to 1997 at this hospital and from 1996 to 1997 at Lister Hospital. Altogether, 268 patients had chlamydial infection (144 men, 124 women). The mean age of the men was 26.8 years (range 16-63) and of the women 23.6 years (16-45).

Contacts of 129 of the 144 male patients $(90 \%)$ were notified either by contact slip or verbally by the index patient. Twelve patients were unable to inform partners as they were casual and unknown, and in three cases patients did not attend after the diagnosis of chlamydia was available and all attempts to contact them failed. Of the 129 contacts who were notified, 91 $(70 \%)$ attended for investigation; 76 contacts came to our clinic and 15 to another clinic. We do not know whether the other 38 patients attended a clinic or not.

Contacts of 114 of the 124 female patients $(92 \%)$ were notified. Ten patients were unable to notify contacts, in seven cases because they were casual and unknown. Two patients did not attend when the diagnosis was available, and attempts to contact them failed. One patient refused to see the health adviser. Of the 114 contacts who were notified, $83(73 \%)$ attended for investigation; 72 contacts attended our clinic and 11 another clinic. Thirty one were unaccounted for.

Harisadhan Maiti Consultant in genitourinary medicine

Heather Bower Sister Jenny Norrie Health adviser

Department of Sexual Health, Clinic 5, Hertford County Hospital, Hertford SG14 1LP

1 Boag F, Kelly F. Screening for Chlamydia trachomatis. BMJ 1998;316:1474. (16 May.)

2 Johnson AM, Grunl L, Haines A. Controlling genital chlamydial infection. BMJ 1996;313:1160.

\section{New technologies enable screening to be} carried out in schools and the community

EDITOR-Boag and Kelly describe the efforts of the chief medical officer and his advisory committee to develop a plan for screening for and treatment of chlamydial infection in the United Kingdom. ${ }^{1}$ This forward thinking and aggressive stance has the potential to dramatically decrease the incidence of this important pathogen in the United Kingdom. In designing a screening plan, however, the advisory group has limited itself to screening only women, and then only at doctors' surgeries. Such an approach misses the opportunities created by the new DNA amplification technology in screening for chlamydia.

With techniques using the polymerase chain reaction, chlamydia can be reliably detected in urine specimens from both men and women. $^{2}$ We recently showed that women and adolescent girls given only an illustrated brochure as an instructional aid 
were capable of obtaining their own specimens from the vaginal introitus and that these specimens were as good as, if not better, than those obtained by a clinician from the endocervix. ${ }^{3}$ Together, these data mean that screening for chlamydia need no longer be confined to doctors' surgeries, thus greatly expanding the opportunities for community based screening. In fact, urine based screening has recently been successfully used in a screening programme for chlamydia in the United States based on local schools. ${ }^{4}$ Others have successfully used peer educators to obtain urine specimens from their peers at high risk in the community, thus capturing a population of infected males unlikely to ever visit a doctor's surgery. ${ }^{5}$

New technologies create new opportunities. I urge the advisory committee to expand its pilot plan by including community and school based screening for both young men and women. We in the United States must also begin a nationwide approach to screening for chlamydia. The combination of creative and aggressive screening with effective partner notification and a single dose treatment for infection has the potential to markedly reduce rates of infection with this serious pathogen.

Margaret Polaneczky Assistant professor of obstetrics and gynaecology

New York Hospital, Cornell Medical Center, 525 East 68th Street, Box 392, New York, NY 10021 USA

1 Boag F, Kelly F. Screening for Chlamydia trachomatis. $B M$ J 1998;316:1474. (16 Mav.)

2 Marrazzo JM, White CL, Krekeler B, Celum CL, Lafferty WE, Stamm WE, et al. Community-based urine screening for Chlamydia trachomatis with a ligase chain reaction for Chlamydia trachomatis with a ligase

3 assay. Ann Intern Med 1997;127.796-803. . Self-testing for Chlamydia trachomatis infection in Self-testing for Chlamydia tracho
women. Obstet Gynecol 1998;91:375-8.

women. Obstet Gynecol 1998;91:375-8.
4 Cohen DA, Nsuami M, Etame RB, Tropez-Sims S, Abdalian S, Farley TA, et al. A school-based chlamydia Abdalian S, Farley TA, et al. A school-based chlamydia
control program using DNA amplification technology.

5 Gunn RA, Podschun GD, Fitzgerald S, Hovell MF, Farshy $\mathrm{CE}$, Black CM, et al. Screening high-risk adolescent males for Chlamydia trachomatis infection. Obtaining urine specimens in the field. Sex Transm Dis 1998;25:49-52.

\section{Screening for and treatment of chlamydial} infection demand commitment

EDITOR-In their editorial Boag and Kelly discuss the chief medical officer's plan for immediate action on Chlamydia trachomatis. ${ }^{1}$ This plan is a step in the right direction, but it does not go far enough. Nearly all of the recommendations are already going on in several parts of the United Kingdom. A previous study identified age as an independent predictor of sexually transmitted infections after controlling for behavioural characteristics. ${ }^{2}$ Similarly, in my report from Coventry I recommended screening women under $30 .^{3}$ As such, it may be prudent to use 30 rather than 25 .

When chlamydial infection is diagnosed in a female patient, every effort should be made to contact and treat the male partner or partners. Untreated, these men will act as reservoirs of sexually transmitted infections since many of them will be free of symptoms.
On the issue of difficulties with contact tracing, the use of modern techniques for detecting $C$ trachomatis-for example, in urine ${ }^{5}$-and various self sampling methods should increase the population being screened. Further application of these methods in the community should increase yield. Patients (men and women) can then take samples themselves and submit these to their general practitioners, school nurses, or family planning clinics.

Finally, there is the issue of commitment by several groups. These include doctors (specialists in genitourinary medicine, gynaecologists (hospital and community), and general practitioners), politicians, and the press for community education on the subject. The contribution of the pathogen to the nation's morbidity is substantial and can no longer be ignored.

A A Opaneye Consultant in genitourinary medicine Middlesbrough General Hospital, Middlesbrough TS5 5AZ

1 Boag F, Kelly F. Screening for Chlamydia trachomatis. BM 1998;316:1474. (16 May.)

2 Arno JN, Katz BP, McBride, Carty GA, Batteiger BE, Cain VA, et al. Age and clinical immunity to infections with chlamydia trachomatis. Sex Transm Dis 1994;21:47-52.

3 Opaneye AA. Sexually transmitted diseases among women in Coventry, England. JR Soc Health 1997;117:37-40.

4 Harry TC Reproductive tract infections and abortion . Higgin SP, Klapper P, Stun N JK, Baley AS, Gou Moor $\mathrm{R}$, Moore $\mathrm{R}$, et al. Detection of male genital infection wit Chlamydia trachomatis and Neisseria gonorrhoeae using an automated multiplex PCR System (Cobas Amplicor). Int J STD AIDS 1998; 9:21-4.

\section{Other amputees are the greatest help in dealing with limb loss}

EDITOR-Maguire and Parkes describe some of the physical and psychological problems following limb amputation and suggest techniques to prevent, recognise, and treat the difficulties that arise. ${ }^{1}$ In concentrating those who have suffered leg amputations in a specialist rehabilitation unit, we have discovered that the greatest resource is the patients themselves. Although we have a dedicated counselling and psychology service, this has been rendered near redundant by the spontaneous development of a therapeutic community. Our patients have developed a group identity and call themselves the "Hopping Mad Club."

They encourage each other in their rehabilitation, but they also inspect each other's wounds, discuss issues such as phantom pain, and are able to advise each other on many other aspects both directly and indirectly related to their amputations. Patients who are anxious and low in mood are taken into the fold and soon become part of the group. The group insists on being heard and has even picketed the catering manager's office to successfully achieve changes in the menu. The patients have also become, to some extent, a self policing group, and unacceptable behaviour such as sexual harassment of nurses rapidly leads to instruction on appropriate demeanour and behaviour.
The group is self sustaining as many of the discharged patients continue to meet at the hospital on a monthly basis and provide further mutual support. Our team has been delighted to relearn that our most powerful resource is the patients themselves.

Nigel Page Specialist registrar

Jed Rowe Consultant geriatrician

Dysvascular Limb Unit, Moseley Hall Hospital, Birmingham B13 8JE

1 Maguire P, Parkes CM. Coping with loss: Surgery and loss of body parts. BMJ 1998;316:1086-8. (4 April.)

\section{Long term follow up of children with recurrent abdominal pain}

\section{Definition of recurrent abdominal pain was not applied}

EDITOR-Large longitudinal studies of children with recurrent abdominal pain, such as the one Hotopf et al conducted, are needed. Current knowledge is limited, and studies on the long term follow up of patients with recurrent abdominal pain should fill the gaps. Hotopf et al have addressed this important subject by trying to answer two questions, as the title of their paper indicates. ${ }^{1}$ The prevalence of recurrent abdominal pain in their cohort $(2 \%)$ was lower than that reported in cross sectional studies $(8-12 \%))^{23}$ This suggests problems with the collection and reliability of the data.

Hotopf et al's first question was, "Why do children have chronic abdominal pain?" Their study was not, however, designed to answer this question. They did not have enough information and did not look for any to help them identify possible causes of abdominal pain. The subjects of the study were identified from a cohort born in 1946 , and the information was collected at the ages of 7,11 , and 15 . The information could not be verified by further questioning, and Apley's definition of recurrent abdominal pain was not applied. ${ }^{2}$ Hotopf et al described the abdominal pain as recurrent, persistent, and chronic, but interchangeably, which added to the confusion and lack of conviction about the condition in question. Although there is no unifying definition that applies to all cases of recurrent abdominal pain in children, the children were treated as if they were a homogeneous group.

Hotopf et al's second question related to what happens to children with recurrent abdominal pain when they grow up. Without a proper definition of recurrent abdominal pain, their conclusions could be true for any non-specific painful condition. Although Hotopf et al's conclusions are useful to describe any child with recurrent ache and pain of unidentifiable cause, they are not specific to recurrent abdominal pain as described and defined by Apley.

Ishaq Abu-Arafeh Consultant paediatrician Stirling Royal Infirmary, Stirling FK8 2AU

1 Hotopf M, Carr S, Mayou R, Wadsworth M, Wessely S. Why do children have chronic abdominal pain, and what 
happens to them when they grow up? Population based cohort study. BMJ 1998;316:1196-200. (18 April.)

2 Apley J, Naish N. Recurrent abdominal pains: a field survey of 1000 school children. Arch Dis Child 1958;33:165-70.

3 Abu-Arafeh I, Russell G. Prevalence and clinical features of abdominal migraine compared with those of migraine headache. Arch Dis Child 1995;72:413-7.

\section{Authors' reply}

EDITOR-Abu-Arafeh points out the importance of long term follow up of children with recurrent abdominal pain. This was our motive in presenting a long (21 year), large $(\mathrm{n}=3637)$, population based prospective cohort study of children with functional abdominal pain. Most of AbuArafeh's comments relate to the fact that we were unable to use a definition for recurrent abdominal pain that was first used some years after our study had started. ${ }^{1}$ We do not think, however, that this reduces the validity of our findings.

Firstly, Apley's definition, like definitions of most other functional somatic symptoms, is arbitrary. The main reason for using it is that other studies have done so, but there are no other reasons to think that it represents a unique clinical entity; it is a means of labelling a common clinical problem. Secondly, contrary to Abu-Arafeh's assertion, we did explore other causes for chronic pain in the children by assessing their hospital records from the age of $0-15$. Thirdly, the outcome we used is probably a more severe category than recurrent abdominal pain as defined by Apley. We believe that it is likely that the children whom we identified would have met Apley's criteria. Our definition may not have captured Apley's notion of recurrent abdominal pain precisely, but this is offset by the fact that our sample was population based and therefore less prone to systematic biases than studies based purely in clinical settings.

Funding is unlikely to become available nowadays to follow up such a large cohort of children over such a long time, and even if it did, one would have to wait many years for the results. We believe that, in the meantime, the main findings of our paper-that children with persistent abdominal pain come from families with high rates of physical illness and are at increased risk of later anxiety and depression-are useful to help us understand the causes and outcome of functional somatic symptoms in childhood.

Matthew Hotopf MRC clinical training fellow S Wessely Professor

Department of Psychological Medicine, Institute of Psychiatry, London SE5 8AZ

Siobhan Carr Lecturer in paediatrics

Department of Paediatrics, Royal Free Hospital, London NW3 2QG

Richard Mayou Professor

University Department of Psychiatry, Warneford Hospital, Oxford OX3 7JX

M Wadsworth Professor

MRC National Survey of Health and Development, Department of Epidemiology and Public Health, University College London Medical School, London, WC1E 6BT

1 Apley J, Naish N. Recurrent abdominal pains: a field study of 1000 school children. Arch Dis Child 1957;33:165-70.

\section{Central venous catheters and infection}

\section{Surveillance is effective in reducing catheter related sepsis}

Editor-We would like to comment on Cyna et al's survey of various intensive care units with regard to their policy on the routine replacement of central venous catheters. ${ }^{1}$ We agree with the Hospital Infection Control Practices Advisory Committee, which recommends that central venous catheters should not be routinely replaced. ${ }^{2}$ Cyna et al recommend that surveillance of catheter related infection be undertaken and the results expressed as catheter related infections in the bloodstream per 1000 catheter days. We recently showed that this surveillance is effective in reducing episodes of catheter related sepsis and can take as little as two hours a month.

If other intensive care units used similar surveillance programmes then not only could catheter related sepsis be reduced but the efficacy of other traditional practices could be assessed. Furthermore, the necessity and efficacy of new equipment for central lines could be monitored.

E T Curran Senior nurse infection control

M Booth Consultant anaesthetist

J Hood Consultant microbiologist

Royal Infirmary, Glasgow G4 0SF

1 Cyna AM, Hovenden JL, Lehmann A, Rajaseker K, Kalia P. Routine replacement of central venous catheters: telephone survey of intensive care units in mainland Britain. phone survey of intensive care unit

2 Hospital Infection Control Practices Advisory Committee. 2 Hospital Infection Control Practices Advisory Committee Part II: Recommendations for the prevention of nosoco-
mial intravascular device-related infections. Am J Infect

3 Curran ET, Booth MG, Dickson L, Lockhart M, Hood J. 3 Curran ET, Booth MG, Dickson L, Lockhart M, Hood J
Catheter related sepsis in an ICU. In: Eighth annual meeting of the Society of Healthcare Epidemiology of America (SHEA). Orlando: SHEA, 1998. [Abstract S7.]

\section{Routine replacement of central venous} catheters should be retained

EDITOR-The audit of routine replacement of central venous catheters in British intensive care units by Cyna et $\mathrm{al}^{1}$ and the accompanying editorial by O'Leary and Bihari assume that the evidence for recommending a no-change policy is soundly based. It is not.

The American Hospital Infection Control Practice Advisory Committee recommends that non-tunnelled central venous catheters should not be routinely replaced as a method of preventing catheter related sepsis and cites three articles supporting this. ${ }^{2}$ Two compared a change of catheter when indicated with routine guidewire exchange at day 3 and described similar rates of sepsis Since the incidence of sepsis increases with duration of catheterisation, ${ }^{3}$ it is not surprising that a three day policy is practised by a only minority of British intensive care units. The more pertinent comparison, with routine replacement at seven days (the commonest policy in Britain) was made in only one paper. ${ }^{4}$ Although outcomes in patients were similar, the study has been criticised for sparse data and failure to use strict definitions of catheter related bacteraemia.
The meta-analysis quoted in the editorial reviewed only one other study, comparing exchange after seven days with replacement when needed in patients receiving long term dialysis. Although infection rates were similar in the two groups, this study was also criticised for lack of data, and the results may not apply to intensive care units. The authors of the meta-analysis made no specific recommendations but recommended randomised clinical trials of each strategy of catheter management. ${ }^{5}$

Intensive care units that change central venous catheters at seven days may also be influenced by the 1994 report of the working group of the Hospital Infection Society and the Royal College of Physicians, which stated: "It would be unusual for central venous catheters to be left in-situ for more than 7 days."

Intensive care units are epicentres for multiresistant micro-organisms, because of the severity of patients' illness and overuse of antimicrobial agents. In our experience, a policy of routinely replacing central venous catheters at a new site after seven days has minimised the use of empirical treatment with glycopeptide antibiotics for catheter related sepsis, while morbidity has been minimal. Sound, randomised clinical trials are required on which to base those policies.

R P D Cooke Consultant medical microbiologist

N A Watson Director of intensive care

K Myerson Consultant anaesthetist

R S Umasankar Consultant medical microbiologist

J Cook Consultant anaesthetist

Departments of Medical Microbiology and

Intensive Care, District General Hospital,

Eastbourne, East Sussex BN21 2UD

1 Cyna AM, Hovenden JL, Lehmann A, Rajaseker K, Kalia P. Routine replacement of central venous catheters: teleunits in mainland Britai BMJ 1998;316:1944-5. (27 June.)

2 Hospital Infection Control Practice Advisory Committee. Part II: Recommendations for the prevention of nosocoPart II: Recommendations for the prevention of nosoco-
mial intravascular device-related infections. Am J Infect mial intravascular device

3 Elliot TSJ, Faroqui MH, Armstrong RF, Hanson GC. Elliot TSJ, Faroqui MH, Armstrong RF, Hanson GC.
Guidelines for good practice in central venous catheterisaGuidelines for good practice in cen
tion. J Hosp Infect 1994;28:163-76.

4 Eyer S, Brummitt C, Crossley K, Siegel R, Cerra F. Catheter related sepsis: prospective, randomised study of three methods of long-term catheter maintenance. Crit Care Med 1990;18:1073-9.

5 Cook D, Randolph A, Kemerman P, Cupido E, King D, Soukup C, et al. Central venous catheter replacement strategies: a svstematic review of the literature. Crit Care Med 1997;25:1417-24

\section{Colonisation of lines does not cause complications, but insertion does 1}

EDitor-We read with interest the paper by Cyna et al about the routine replacement of central venous catheters in intensive care units $^{1}$ and agree with the sentiments expressed by O'Leary and Bihari in their accompanying editorial. ${ }^{2}$ While I was working in the intensive care unit of the Royal Berkshire Hospital in Reading, a prospective four month study of central venous line insertions was undertaken. ${ }^{3}$ During the study 104 people were admitted to the unit. A total of 154 insertions of multilumen central venous pressure lines, haemofiltration lines, and pulmonary artery catheter introducers were done in 74 patients studied. The lines were left in situ for a mean of 4.2, 4.8, and 4.3 days respectively. 
The colonisation rate, assessed by the proportion of positive results of culture of the line tip, was $36 \%$ (25\% after adjustment for the number of lines removed at days 1 and 2 that did not undergo culture). The risk of colonisation increased over time but was already high by day 3 , which indicates that there would be no benefit from planning line changes for day 5 or later. No evidence of a catheter related infection was found in any patient.

Our rates of catheter related complications were in line with those in other studies. There were 24 complications (16\%), most of them minor-for example, difficult insertion, haematoma, etc. The incidence of serious complications was $2 \%$.The conclusion was that in the Royal Berkshire Hospital's intensive care unit there was no indication for planned replacement of lines; rather, lines should be resited on clinical grounds alone.

Colonisation has often been measured in studies of scheduled removal of lines versus removal when indicated and studies of choosing a new site versus wiring the same site for replacement. Although colonisation of lines is quite common, there is little evidence that it has serious sequelae. Complications related to insertion, however, may certainly occur-for example, pneumothorax, haemothorax, arrhythmias. The literature does not support scheduled replacement of lines to avoid the rare, if serious, complication of catheter related sepsis, given that the incidence of other serious complications related to insertion is much higher. ${ }^{4}$

Local conditions may vary-insertion techniques, the type of catheter used, the site of insertion, and the care of the catheter subsequently, as well as the local microbiological flora. All of these may affect the infective and mechanical complication rates. Units should therefore perform their own studies before deciding on a policy with regard to scheduled line replacement and to whether lines should be rewired or resited.

Frances Bernau Training fellow in cardiac anaesthesia

Nuffield Department of Anaesthetics, John Radcliffe Hospital, Oxford OX3 9DY

mcnabernau@enterprise.net

T J Dexter Consultant anaesthetist Wycombe General Hospital, Buckinghamshire HP11 2TT

1 Cyna AM, Hovenden JL, Lehmann A, Rajaseker P, Kalia P. Routine replacement of central venous catheters: tele-

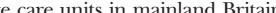
phone survey of intensive care unit

2 BMJ 1998;316:1944-5. (27 June). O'Leary M, Bihari D. Central venous cathe
change? BMJ 1998;316:1918-9. (27 June).

change? BMJ 1998;316.1918-9. (27 June). Bernau FL, Parke T, Dexter TJ. An audit of central line
practice on the intensive care unit of the Roval Berkshire practice on the intensive care unit of the Royal Bet
Hospital, Reading. Clin Intensive Care 1997;8:106.

4 Cook D, Randolph A, Kernerman P, Cupido C, King D, 4 Cook D, Randolph A, Kernerman P, Cupido C, King D,
Soukup C, Brun-Buisson C. Central venous catheter Soukup C, Brun-Buisson C. Central venous catheter
replacement strategies: a systematic review of the

replacement strategies: a systematic revic
literature. Crit Care Med 1997;25:1417-24.

This letter was posted on the $B M J$ website on 27 July.

Use of antimicrobial catheters needs to undergo trials

EDIToR-Cyna et al's survey of intensive care units in mainland Britain showed that most central venous catheters are routinely changed at seven days. ${ }^{1}$ In the accompany- ing editorial O'Leary and Bihari explore the reasons for this approach. ${ }^{2}$ One reason may be that clinicians consider that this practice offers a benefit-risk advantage, possibly on the basis of an inaccurate perception of the incidence of catheter colonisation or infection, which can lead to feelings of guilt by the doctor. A more likely reason is the difficulty in diagnosing sepsis related to central venous catheters, particularly in patients in intensive care units.

The general features of septicaemia related to central venous catheters are nonspecific and indistinguishable from features of infection arising from other sources. The correlation between clinical diagnosis and microbiological confirmation is also poor The key clinical and microbiological findings have, however, been well documented recently. ${ }^{3}$ It therefore seems logical to retain central venous catheters in situ, provided that regular clinical and microbiological surveillance based on well defined criteria is carried out. ${ }^{3}$ This should include regular audit and recording of the rate of infection related to central venous catheters per day of catheterisation rather than as a percentage as given by O'Leary and Bihari. Other recent literature, including the latest recommendation by the Centers for Disease Control and Prevention in the United States, ${ }^{4}$ also supports non-routine changing of central venous catheters. If an infection is diagnosed, treatment with antibiotics should be considered before removal of the catheter is deemed necessary, particularly if the infection is caused by coagulase negative staphylococci.

O'Leary and Bihari suggest that the use of catheters impregnated with antimicrobials should be considered. It is important however, that any change in practice is based on well organised, randomised clinical trials. Currently there is only limited clinical evidence of the efficacy of these devices, and there have already been conflicting reports. Concern has also been raised regarding resistance to antimicrobials, which may develop when intravascular catheters coated with antimicrobials are used to treat infection. Multicentre studies are required to evaluate all the factors associated with infections of central venous catheters so that the possible solutions, including the use of antimicrobial catheters, can be evaluated adequately. Without such an approach, antimicrobial catheters will be introduced on the basis of limited data and the opportunity for appropriate and well controlled studies will be lost. We will then be in the same position as that identified by Cyna et al regarding the routine replacement of central venous catheters. ${ }^{1}$

Tom Elliott Consultant microbiologist

Muzaffar Faroqui Consultant anaesthetist University Hospital Birmingham NHS Trust, Birmingham B15 2TH

1 Cyna AM, Hovenden JL, Lehmann A, Rajaseker K, Kalia P. Routine replacement of central venous catheters: telephone survey of intensive care units in mainland Britain. BMJ 1998;316:1944-5. (27 June.)

2 O'Leary M, Bihari D. Central venous catheters-time for a change? BMJ 1998;316:1918-9. (27 June.)
3 Maki DG, Mermel LA. Infections due to infusion therapy. In: Hospital infections. 4th ed. Philadelphia: LippincottRaven, 1998.

4 Pearson ML, for the Hospital Infection Control Practices Advisory Committee. Guideline for prevention of intravascular device-related infections. Infect Control Hosp Epidemiol 1996;17:438-73.

5 Widmer AF. Central venous catheters. In: Seifert H, Jansen B, Farr BM, eds. Catheter-related infections. New York: Marcel Dekker, 1997:183-215.

\section{Effects of ambulance response times are being evaluated}

EDITOR-In his editorial Evans called for a review of the effects of improving ambulance response times on the outcome of coronary emergencies outside hospital. ${ }^{1}$ This research is already under way. Over a two year period, we are investigating, on behalf of the Department of Health, the effect that changes in response times are having in four ambulance service areas. These changes are occurring as the services seek to implement the new standard that $75 \%$ of calls involving chest pain or other potentially serious signs should be responded to within 8 minutes (not $90 \%$ of all calls, as reported by Evans). The research has been designed to detect the size of effect that Norris hypothesises could be achieved (that is, a $7-10 \%$ reduction in the number of fatalities). ${ }^{2}$

However, as Ruston et al have pointed out, ${ }^{3}$ a bigger effect could probably be achieved if patients sought medical help earlier in response to warning signs. Evans suggests this requires more public education. A better solution might be to give patients and witnesses instant access to simple, confidential, and appropriate information about what to do at the point of need. We hope that the telephone lines for immediate care and advice, known as NHS Direct, that are being piloted in three areas of the United Kingdom-which we are also evaluating for the Department of Healthwill reduce the time to seek help and lead to earlier medical care and better outcomes.

Jon Nicholl Professor

Jill Willoughby Personal assistant to Professor Nicholl Medical Care Research Unit, University of Sheffield, Sheffield S1 4DA

\footnotetext{
1 Evans T. Cardiac arrests outside hospital. BMJ 1998;316:1031-2. (4 April.)

2 Norris RM. Fatality outside hospital from acute coronary events in three British health districts, 1994-5. BMJ 1998;316:1065-70. (4 April.)

3 Ruston A, Clayton J, Calnan M. Patients' action during Ruston A, Clayton J, Calnan M. Patients' action during
their cardiac event: qualitative study exploring differences and modifiable factors. BMJ 1998;316:1060-4. (4 April.)
}

\section{Correction}

The hot air on passive smoking

An error occurred in the table accompanying this letter by Nemery et al (1 August 1998). The row of figures relating to $\mathrm{J} \mathrm{R}$ Idle should have read 159, 12, 12, and 4 (not 159, 12, 1, and 24 , as published). 